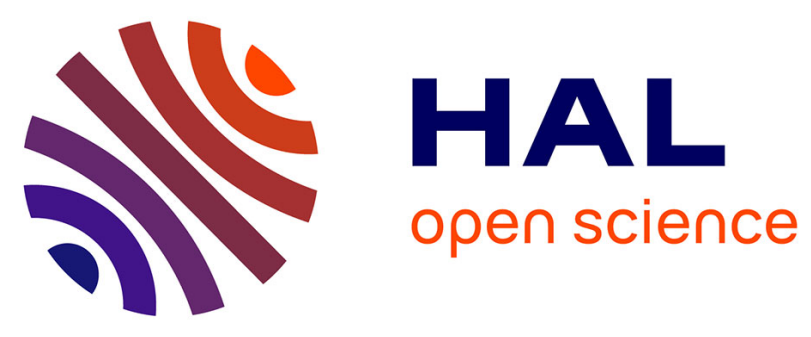

\title{
On the Interplay of Business Process Modeling and Missions in Systems-of-Information Systems
}

Valdemar Vicente Garcia Neto, Everton Cavalcante, Jamal El Hachem, Daniel Soares Santos

\section{- To cite this version:}

Valdemar Vicente Garcia Neto, Everton Cavalcante, Jamal El Hachem, Daniel Soares Santos. On the Interplay of Business Process Modeling and Missions in Systems-of-Information Systems. SESoSWDES workshop in the International Conference on Software Engineering, May 2017, Buenos Aires, Argentina. 10.1109/JSOS.2017.7 . hal-01908421

\section{HAL Id: hal-01908421 https://hal.science/hal-01908421}

Submitted on 30 Oct 2018

HAL is a multi-disciplinary open access archive for the deposit and dissemination of scientific research documents, whether they are published or not. The documents may come from teaching and research institutions in France or abroad, or from public or private research centers.
L'archive ouverte pluridisciplinaire HAL, est destinée au dépôt et à la diffusion de documents scientifiques de niveau recherche, publiés ou non, émanant des établissements d'enseignement et de recherche français ou étrangers, des laboratoires publics ou privés. 


\title{
On the Interplay of Business Process Modeling and Missions in Systems-of-Information Systems
}

\author{
Valdemar Vicente Graciano Neto ${ }^{1,2,3}$, Everton Cavalcante ${ }^{4}$, Jamal El Hachem ${ }^{5}$, Daniel Soares Santos ${ }^{1}$ \\ ${ }^{1}$ University of São Paulo, São Carlos, Brazil \\ ${ }^{2}$ IRISA-UMR CNRS/Université Bretagne-Sud, Vannes, France \\ ${ }^{3}$ Universidade Federal de Goiás, Goiânia, Brazil \\ ${ }^{4}$ Federal University of Rio Grande do Norte, Natal, Brazil \\ ${ }^{5}$ Université de Pau et des Pays de l'Adour, Mont-de-Marsan, France \\ valdemarneto@usp.br, everton@dimap.ufrn.br, jamal.elhachem@univ-pau.fr, danielss@usp.br
}

\begin{abstract}
Systems-of-Information Systems (SoIS) are a class of systems-of-systems (SoS) in which constituents are information systems and exhibit a strong business-oriented nature. Existing mission notations and approaches for specifying missions in SoIS have not been able to cope with particular characteristics of this class of systems, including the sequence and interdependence among activities, roles definition, and the dynamics of constituents to freely join or leave a SoIS. In this context, we claim that Business Processes Modeling (BPM) techniques and models could complement such approaches, offering support for requirements specification and an additional viewpoint for architectural specification of SoIS. This position paper outlines a discussion on the potential of BPM to complement mission specification modeling notations, as well as it presents some research directions and challenges for modeling missions in SoIS.
\end{abstract}

\section{INTRODUCTION}

Systems-of-Information Systems (SoIS) are a class of systems-of-systems (SoS) in which constituents are strictly software-intensive information systems [1], [2], [3], [4], [5]. Both SoS and SoIS are concerned with the accomplishment of missions. In the SoS context, missions can be viewed as a set of goals to be accomplished by (i) performing tasks based on capabilities of constituent systems, i.e., what they can do to perform such tasks, and (ii) interactions among constituent systems leading to emergent behaviors. Individual missions are realized by constituent systems themselves whereas global missions of an SoS are accomplished through emergent behaviors. [6], [7].

As SoS, SoIS are often formed by constituent systems that are managed and operated by independent organizations [8]. These constituents in a SoS can cooperate to accomplish interorganizational missions. Considering the current industrial practices, it is not uncommon the emergence of temporary alliances of companies to achieve specific and temporary goals within the context of a project [9]. In this sense, SoIS can support inter-organization business processes, making this class of systems to have a strong business-oriented nature. This raises the need of establishing representation and management strategies to support concepts such as sequence of activities and interdependence between roles and goals [5], [10].
We have noticed that current SoIS engineering approaches and notations do not support modeling missions in the SoIS domain. Existing notations such as SysML ${ }^{1}$ and $\mathrm{UML}^{2}$ activity diagrams require adaptations (profiles) to represent cooperating constituent systems since they do not have native support to model these missions. And mKAOS approach do not hold the notion of inter-dependent activities [7]. For SoIS, a notation for specifying missions should encompass (i) a business-oriented nature, (ii) the concept of process with a sequence of inter-dependent activities, and (iii) flexibility for adaptations due to the business dynamics. In this paper, we claim that business process notations and mission modeling languages can interplay to leverage missions modeling in SoIS.

The remainder of this paper is organized as follows. Section II introduces research directions and challenges. Finally, Section III contains some concluding remarks.

\section{RESEARCH DiRECTIONS AND ChALLENGES}

We glimpse that BPM has potential to complement mission specification. We hereby outline some challenges for missionmodeling based on business processes in the context of SoIS.

Emerging requirements and flexible business-oriented missions. BPM has been commonly used to represent interorganizational/collaborative business processes in industry. The main challenge would be how to use it to represent a business process when participating organizations can join or leave the SoIS mission at runtime. Moreover, it is necessary to consider new requirements arising from emergent behaviors discovered in SoIS or potential business innovations due to new arrangements of existing capabilities [10]. New missions can be designed based on business processes, and current business processes must be flexible to fit those requirements.

Relationship between mission modeling and BPM. The interplay between mission modeling and BPM in SoIS can be properly realized when mapping mission concepts to BPM notations. For instance, Business Process Execution Language

\footnotetext{
${ }^{1}$ http://www.omg.org/spec/SysML/1.4/

${ }^{2}$ http://www.uml.org/
} 
(BPEL) is a service orchestration language commonly associated with BPM in the context of Service-Oriented Architecture (SOA), providing strategies for service discovery and architectural self-adaptation [11]. Therefore, BPM models associated with mKAOS mission models can be mapped, via model transformation, to BPEL models with self-adapting characteristics. This approach can be especially useful for an SoIS that adopts SOA as its underlying platform, in which a centralized entity (directed SoIS) orchestrates constituents.

Goal granularity and matching. Goal-based approaches often decompose missions into sub-goals. However, identifying potential constituents that could join an SoIS to increase its capabilities or improve the provided services provided may rise a problem of goal granularity and matching. BPM approaches and tools need to be drawn to automatically define an optimal granularity of sub-goals. Strategies based on ontology and semantic representation can also be established to automate the discovery of constituents with the capabilities needed to solve a sub-goal.

Reuse and/or adaptation of BPM tools to SoIS. In a previous work, we have presented Sinfonia, a collaborative approach based on a software component for modeling and executing business processes in a model-based information system application framework [12]. This tool supports the execution of flexible business processes, i.e., those that can have their flow changed at runtime. As flexibility is a key concern in business process management [13], this type of approach could be extended and adapted to cover SoIS needs and associated to mission modeling in SoIS.

Handling conflicts. In the SoIS context, conflicts among goals may arise for a variety of reasons, such as: (i) the existence of a broader range of stakeholders including both stakeholders of constituents and the stakeholders of the overall SoIS, each one with different interests in the SoIS; (ii) conflicts in the relationship between constituents and the SoIS due to their managerial independence; (iii) conflicts arisen from interactions among constituents due to their operational independence; and (iv) the fact that a given constituent might simultaneously belong to more than one SoIS. Therefore, it is necessary to provide strategies and solutions to tackle these different scenarios that may result in conflicting goals and to assess the impact of such conflicts in the operation of the SoIS and its constituents.

\section{FINAL REMARKS}

In this paper, we argued the potential of BPM to complement mission specification in the context of SoIS. Due to the predominant business-oriented nature of this particular type of SoS, specific notations are required to capture the characteristics exhibited by SoIS. BPM can be useful in this effort since: (i) it is possible to adopt well-established tools supporting BPM to allow for SoIS mission modeling, simulation, automation, and monitoring; (ii) BPM models bring the possibility of converting them to the BPEL format, thereby allowing for processing and compilation; (iii) a BPM metamodel is available, thus allowing for model transformations to other models, including code generation; and (iv) there are well-established notations, which reduce learning curve and can facilitate mission modeling in SoIS.

Missions are a concept from SoS domain while business processes come from the Information Systems domain. Both business processes and SoIS do not exhibit the notions of missions yet. As business processes represent a key concern for the Information Systems domain [14] and missions are a key concern for SoS [15], it is of paramount important to fit these concepts in SoIS research.

\section{REFERENCES}

[1] B. Carlsson and R. Stankiewicz, "On the nature, function and composition of technological systems," Journal of Evolutionary Economics, vol. 1, no. 2, pp. 93-118, 1991. [Online]. Available: http://dx.doi.org/10.1007/BF01224915

[2] S. Breschi and F. Malerba, "Sectoral innovation systems: technological regimes, schumpeterian dynamics, and spatial boundaries," Systems of innovation: Technologies, institutions and organizations, pp. 130-156, 1997.

[3] M. Saleh and M.-H. Abel, "Information Systems: Towards a System of Information Systems," in KMIS 2015 7th International Conference on Knowledge Management and Information Sharing, Lisbon, Portugal, Nov 2015, pp. 193-200.

[4] S. Majd, A. Marie-Hélène, and M. Alok, On the Move to Meaningful Internet Systems: OTM 2015 Workshops. October 26-30, 2015. Proceedings. Rhodes, Greece: Springer, 2015, ch. An Architectural Model for System of Information Systems, pp. 411-420.

[5] V. V. Graciano Neto, F. Oquendo, and E. Y. Nakagawa, "Systems-ofsystems: Challenges for information systems research in the next 10 years," in Big Research Challenges in Information Systems in Brazil (2016-2026), ser. GRANDSI-BR/SBSI, Florianópolis, Brazil, 2016, pp. $1-3$.

[6] E. Silva, E. Cavalcante, T. Batista, F. Oquendo, F. C. Delicato, and P. F. Pires, "On the characterization of missions of systems-of-systems," ser. ECSAW '14. Vienna, Austria: ACM, Aug. 2014, pp. 26:1-26:8.

[7] E. Silva, T. Batista, and E. Cavalcante, "A mission-oriented tool for system-of-systems modeling," in SESoS. Florence, Italy: IEEE, May 2015, pp. 31-36.

[8] M. W. Maier, "Architecting principles for systems-of-systems," Systems Engineering, vol. 1, no. 4, pp. 267-284, 1998.

[9] I. Frame, K. Austen, M. Calleja, M. Dove, T. White, and D. Wilson, "New tools to support collaboration and virtual organizations," Philosophical Transactions of the Royal Society of London A: Mathematical, Physical and Engineering Sciences, vol. 367, no. 1890, pp. 1051-1056, 2009. [Online]. Available: http://rsta.royalsocietypublishing.org/content/367/1890/1051

[10] C. A. Lana, N. M. Souza, M. E. Delamaro, E. Y. Nakagawa, F. Oquendo, and J. C. Maldonado, "Systems-of-systems development: Initiatives, trends, and challenges," ser. CLEI '16. Valparaiso, Chile: IEEE, Oct. 2016, pp. 1-10.

[11] K. Pant and M. B. Juric, Business process driven SOA using BPMN and BPEL: From business process modeling to orchestration and service oriented architecture. Packt Publishing Ltd, 2008.

[12] J. L. de Oliveira, L. F. B. Loja, and V. V. Graciano Neto, "A Component for Business Processes Management in Information Systems (In Portuguese)," ser. SBSI '11, Salvador, Brazil, May 2011, pp. 250-261.

[13] G. Kaes, S. Rinderle-Ma, R. Vigne, and J. Mangler. Berlin, Heidelberg: Springer Berlin Heidelberg, 2014, ch. Flexibility Requirements in RealWorld Process Scenarios and Prototypical Realization in the Care Domain, pp. 55-64. [Online]. Available: http://dx.doi.org/10.1007/ 978-3-662-45550-0_8

[14] S. M. Shafer, H. J. Smith, and J. C. Linder, "The power of business models," Business horizons, vol. 48, no. 3, pp. 199-207, 2005.

[15] E. Silva, E. Cavalcante, T. Batista, and F. Oquendo, "Bridging missions and architecture in software-intensive systems-of-systems," in ICECCS'16. Dubai, United Arab Emirates: IEEE, 2016, pp. 1-6. 